\title{
ERRATUM
}

\section{get organised: the 'do's' preceding successful field research}

floriang g. kern ${ }^{a, \star}$ and janis vossiek ${ }^{b}$

aDepartment of Politics and Public Administration, University of Konstanz,

P.O. Box 90, Konstanz 78457, Germany

E-mail: florian.kern@uni-konstanz.de

${ }^{b}$ Department of Politics and Public Administration, University of Konstanz,

P.O. Box D 79, Konstanz 78457, Germany

E-mail: janis.vossiek@uni-konstanz.de

${ }^{*}$ Corresponding author.

doi:10.1057/eps.2014.51; published online 16 January 2015

Correction to: european political science advance online publication, 12 December 2014; doi: $10.1057 /$ eps.2014.45

In the originally published version of this paper, the first author was listed as

Floriang G. Kern

This was incorrect. The correct name should have been:

Florian G. Kern

We apologise for this error. 